\title{
Gingival crevicular fluid oxidative stress level in patients with periodontal disease and hyperlipidemia
}

\author{
Müge LUTFIOĞLU(a) \\ Ahmet AYDOĞDU(b) \\ Vadim Ekrem ATABAY(c) \\ Elif Eser SAKALLIOĞLU(a) \\ Bahattin AVCI(d) \\ (a) Ondokuz Mayis University Faculty of \\ Dentistry, Department of Periodontology, \\ Samsun, Turkey. \\ (b)Bezmi Alem University Faculty of \\ Dentistry, Department of Periodontology, \\ Istanbul, Turkey. \\ (c)Samsun State Oral Health Care \\ Center, Department of Periodontology, \\ Samsun, Turkey. \\ (d) Ondokuz Mayis University Faculty of \\ Medicine, Department of Medical \\ Biochemistry, Samsun, Turkey.
}

Declaration of Interest: The authors certify that they have no commercial or associative interest that represents a conflict of interest in connection with the manuscript.

\section{Corresponding Author: \\ Müge LUTFIOGLU \\ E-mail: mugelutfioglu@hotmail.com}

hitps://doi.org/10.1590/1807-3107bor-2017.vol31.0110

\begin{abstract}
This study aimed to assess the impact of hyperlipidemia on healthy and diseased periodontal tissue by evaluating oxidative stress biomarkers in gingival crevicular fluid (GCF). Clinical periodontal parameters and blood serum lipid, GCF malondialdehyde (MDA), protein carbonyl (PC), and total antioxidant capacity (TAOC) levels were evaluated in six age and sex-matched groups ( $\mathrm{n}=15$ each) of normolipidemic and hyperlipidemic individuals as follows: normolipidemic + periodontally healthy $(\mathrm{H})$, normolipidemic + gingivitis $(\mathrm{G})$, normolipidemic + chronic periodontitis $(\mathrm{CP})$, hyperlipidemic + periodontally healthy $(\mathrm{HH})$, hyperlipidemic + gingivitis (HG), and hyperlipidemic + CP (HCP). GCF MDA, and PC levels varied among groups, with patients with periodontitis having the highest MDA and PC levels $[\mathrm{CP}>\mathrm{G}>\mathrm{H}(\mathrm{p}<0.01)$ and HCP $>$ HG $>\mathrm{HH}(\mathrm{p}<0.01)]$ and the lowest TAOC levels $[\mathrm{CP}<\mathrm{G}<\mathrm{H}(\mathrm{p}<0.01)$ and $\mathrm{HCP}<\mathrm{HG}<\mathrm{HH}(\mathrm{p}<0.01)]$. Furthermore, paired comparisons showed MDA and PC levels to be higher and TAOC levels to be lower in HCP compared with NCP $(p<0.01)$. In patients with hyperlipidemia, GCF, MDA, and PC levels positively correlated with clinical assessments and serum triglycerides (TG), total cholesterol (TC), and low-density lipoprotein cholesterol (LDL) levels and negatively correlated with serum high-density lipoprotein cholesterol (HDL) levels, whereas GCF TAOC levels negatively correlated with clinical assessments and serum TG, TC, and LDL levels, but positively correlated with serum HDL levels $(p<0.01)$. In normolipidemic patients, GCF, MDA, and PC levels positively correlated with clinical assessments and serum TG levels and negatively correlated with serum HDL levels, whereas GCF TAOC levels negatively correlated with clinical assessments and serum TG levels and positively correlated with serum HDL levels $(p<0.01)$. In conclusion, abnormal serum lipid subfractions could be considered a risk factor for enhancing oxidative stress in GCF in the presence of periodontal disease.
\end{abstract}

Keywords: Hyperlipidemia; Periodontal Disease; Malondialdehyde; Oxidative Stress.

\section{Introduction}

Periodontal disease is associated with reduced antioxidant capacity Accepted for publication: Nov 8, 2017 Last revision: Nov 23, 2017 and increased oxidative damage in the oral cavity. Oxidative damage is suggested to be a common risk factor for several inflammatory disorders 
by inducing inflammatory reactions. ${ }^{1}$ Oxidative stress (OS) promotes the pathophysiological progression of periodontal disease by triggering local and systemic inflammatory responses. . $, 3,4,5^{-1}$

Hyperlipidemia, i.e., elevated serum lipid levels, is thought to cause imbalance in the production of highly reactive molecular species and antioxidant defenses, leading to increased OS and creating a proinflammatory state that predisposes subjects to infections. ${ }^{1,6}$ Hyperlipidemia is a risk factor for atherosclerotic diseases by causing hyperactivity of white blood cells, ${ }^{7}$ and this hyperactivity leads to an increase in production of reactive oxygen species (ROS) and lipid peroxidation. ${ }^{8}$

In periodontal disease, the interaction between host immune response and pathogens stimulates cytokine expression and subsequently generates excessive ROS-derived radicals..$^{9,10}$ ROS-derived radicals play an important role in the inflammatory process by promoting damage of proteins, DNA, carbohydrates, and lipids. ${ }^{10,11}$ Moreover, these OS-related mediators have frequently been associated with inflammatory responses, specifically in relation to chronic periodontitis (CP). ${ }^{1}$

When ROS attacks proteins and lipids, a series of nonenzymatic reactions occur to produce a large variety of intermediate and end products. OS may be evaluated either by observing by-products of the interaction of ROS with lipids, proteins, and DNA or by examining alterations in total antioxidant capacity (TAOC). Tissue protein carbonyl (PC) content is a non-enzymatic, oxidative, post-translational modification of protein carbonylation that is often used as a biomarker of OS. ${ }^{12}$ For measuring biological lipid oxidation, malondialdehyde (MDA) is a frequently used marker because of its high specificity. ${ }^{13}$ However, given the potential for synergistic effects among different antioxidants, it has been suggested that measuring TAOC may provide a more accurate and extensive assessment of an individual's antioxidant status and the level of protection offered to host cells subjected to OS than separately measuring individual antioxidant molecules. ${ }^{14}$

Recent studies have produced inconsistent results regarding how periodontal status is affected by alterations in blood-lipid composition, namely, high levels of serum total cholesterol (TC), low-density lipoprotein cholesterol (LDL), and triglycerides (TG) and low levels of high-density lipoprotein cholesterol (HDL). The interference of different serum lipid subfractions and periodontal infection has been reported by several researchers, $15,16,17$ whereas others have reported either no connection ${ }^{18}$ or limited connection. ${ }^{6,19}$ Till date, a limited number of studies have separately reported the connection between increased OS and hyperlipidemia ${ }^{11,20}$ and increased OS and periodontitis. ${ }^{2,3,4}$ To the best of our knowledge, only one clinical-based study ${ }^{11}$ examined OS parameters in patients with periodontitis with hyperlipidemia, and that study measured parameters systemically in blood serum, not locally in GCF or gingival tissue.

Based on the findings of previous studies, we hypothesized that hyperlipidemia, which is characterized by abnormal serum lipid levels, may aggravate periodontal infection, presumably by altering the OS status of periodontal tissue. Therefore, this case-controlled study investigated 1 ) the effects of hyperlipidemia on oxidative changes in GCF content, i.e., PC, MDA, and TAOC levels, in patients with differing periodontal health status and 2) the correlation between serum lipid levels and GCF PC, MDA, and TAOC levels.

\section{Materials and Methods}

\section{Study population}

This case-controlled study was conducted on 45 patients with hyperlipidemia ( 23 females, 22 males) and 45 age- and sex-matched normolipidemic controls (23 females, 22 males) jointly recruited by the Ondokuz Mayis University Faculty of Dentistry's Department of Periodontology and the Faculty of Medicine's Department of Endocrinology and Metabolic Diseases in Samsun, Turkey, between January 2013 and August 2014. Patients with hyperlipidemia were selected among patients who presented at the Department of Internal Medicine for routine control examinations, and normolipidemic controls were randomly selected among subjects referred to the Department of Periodontology for either dental treatment or check-ups. All controls underwent detailed systemic examinations. Ondokuz Mayis University Medical Research Ethics Committee 
confirmed the study protocol, and written informed consent was obtained from the study participants in accordance with the Helsinki Declaration, version 2002 (Clinical trial number, NCT02808130).

The general inclusion criteria were a) age $\geq 18$ years and having $\geq 16$ teeth, b) no periodontal therapy within the previous 6 months, c) no chemotherapy and no antilipidemic drug treatment within 6 weeks before data collection, and d) no history of cigarette consumption. The exclusion criteria were a) medical therapy for cancer, rheumatoid arthritis, diabetes mellitus, cardiovascular disease, or any other systemic disease affecting lipid metabolism (i.e., impaired glucose tolerance and metabolic syndrome); b) pregnancy, menopause, or lactation; d) immune system deficiency; d) ongoing or starting any drug therapy that could affect the clinical characteristics of periodontitis or lipid metabolism; and e) use of systemic antimicrobials within 6 weeks before data collection.

The study participants were grouped as follows: Group H: normolipidemic + periodontally

healthy subjects

Group G: normolipidemic + gingivitis

Group CP: normolipidemic + generalized CP

Group HH: hyperlipidemic + periodontally

healthy subjects

Group HG: hyperlipidemic + gingivitis

Group HCP: hyperlipidemic + generalized CP

Clinical evaluations and GCF collection were performed by a single examiner, and the following laboratory procedures were performed by another researcher blinded to the study groups.

\section{Clinical evaluations}

The following clinical parameters were evaluated to determine the periodontal status of the subjects: Silness \& Löe plaque index (PI), ${ }^{21}$ Löe \& Silness gingival index (GI), ${ }^{22}$ probing pocket depth (PPD), clinical attachment level (CAL), and bleeding on probing (BOP). Measurements were performed at six sites per tooth (mesiobuccal, midbuccal, distobuccal, mesiolingual, midlingual, and distolingual) using a calibrated Williams periodontal probe (Nordent Manufacturing Inc., Elk Grove Village, IL, USA). GCF samples were subsequently obtained from the deepest six sites fitting the criteria described below.

\section{Metabolic parameters}

Hyperlipidemia was diagnosed at least 3 months before the study based on an abnormal value for at least one element of the lipid profile using the following cutoff points according to laboratory recommendations: $\mathrm{TC},>200 \mathrm{mg} / \mathrm{dL} ; \mathrm{TG},>200 \mathrm{mg} / \mathrm{dL}$; LDL cholesterol, > $130 \mathrm{mg} / \mathrm{dL} ;$ and HDL, <35 mg/dL). ${ }^{23}$ No distinctions were drawn among hyperlipidemia type. ${ }^{15}$ Samples were obtained from an antecubital vein after a 12-h fasting period. Biochemical assessments of serum lipid levels were performed in the clinical Biochemistry Laboratory of the Ondokuz Mayis University Hospital using routine enzymatic methods.

\section{GCF sampling and processing}

In total, $90 \mathrm{GCF}$ samples were taken per group (15 subjects $\times 6$ sites). The samples were collected from the deepest six sites in the $\mathrm{CP}$ group to maintain consistency of sampling and from corresponding sites with BOP in the gingivitis group and corresponding sites without BOP in the periodontally healthy group.

On the day after periodontal status assessment, GCF samples were collected by periopaper strip (Oraflow Inc., Plainview, NY, USA) between 8:00 am and 10:00 a.m. The supragingival plaque was removed from the sampling site, and the area was carefully isolated with cotton rolls to prevent saliva contamination of the strips and gently air dried. The periopaper strip was placed into the gingival crevice up to $1 \mathrm{~mm}$ or until mild resistance was felt and left in the crevice for $30 \mathrm{~s}$. Any strip contaminated by bleeding or exudate was discarded. GCF sample volumes $(\mu \mathrm{L})$ were measured using Periotron 8000 (Periotron ${ }^{\circledR}$ 8000, Pro Flow Inc., Amityville, NY, USA). The strips were individually placed in plastic Eppendorf microcentrifuge tubes and stored at $-80^{\circ} \mathrm{C}$ until processing.

The GCF elution directions of Curtis et al. were used; samples were incubated and centrifuged at $4^{\circ} \mathrm{C} .{ }^{24}$ Commercially available ELISA kits were utilized, and assays were applied according to the manufacturers' instructions to examine PC (Oxiselect Protein Carbonyl ELISA Kit, Cell Biolabs Inc., San Diego, CA, USA; Cat. No. STA-310), GCF MDA (Bioxytech, MDA586, OxisResearch, Foster City, CA, USA, Cat. No. 21044), and TAOC levels (ImAnOx-TAS/TAC Kit, 
Immundiagnostik AG, Germany, Cat. No. KC 5200). Spectrophotometric device with wavelengths of 450 $\mathrm{nm}$ and $550 \mathrm{~nm}$ was used for ELISA readings. The total PC, MDA, and TAOC levels in GCF sampled over a 30-s period were recorded and subjected to statistical analysis.

\section{Statistical analysis}

The statistical software program SPSS Inc. (SPSS v.21.0, Chicago, IL, USA) was used for statistical analysis, with results presented as means and standard error of mean. The Shapiro-Wilk test was performed to examine normality, and parametric tests were performed to analyze the data. The Levene test showed non-homogeneity of variance, the Welch ANOVA test was used to identify statistical differences among the groups, and Tamhane's T2 tests were used for posthoc pair-wised group comparisons. The comparisons between sexes were determined by non-parametric chi-square test. Pearson's correlation tests were used to evaluate the correlations between clinical indices and biochemical parameters. A $p$ value of $<0.05$ was considered statistically significant. The minimum requirement of 13 participants per group to compare the data between groups at $\alpha=0.05$ with a power value of $80 \%$ was determined by power analysis calculations.

\section{Results}

A total of 90 subjects (45 systemically healthy patients and 45 patients with hyperlipidemia) participated in this study. Age and sex distributions and clinical assessments of the study groups are summarized in Table 1. Age and sex distributions were similar for groups paired according to the periodontal status ( $\mathrm{p}>0.05)$.

The paired comparisons showed no significant differences in PI, GI, or BOP scores between hyperlipidemic and normolipidemic groups, regardless of periodontal status, indicating that these clinical manifestations of periodontal disease were not affected by serum lipid levels ( $p>0.05$ ). Moreover, although paired comparisons showed PPD and CAL measurements to be higher among patients with hyperlipidemia than among normolipidemic subjects with similar periodontal status, these differences were not statistically significant $(p>0.05)$. However, for both hyperlipidemic and normolipidemic groups, clinical parameters significantly varied between periodontally healthy subjects and those with gingivitis or periodontitis $(\mathrm{p}<0.05)$.

Serum lipid and GCF PC, MDA, and TAOC levels of the groups are given in Table 2. Serum lipid levels significantly varied between the hyperlipidemic and normolipidemic groups $(p<0.05)$. Among the normolipidemic groups, all serum lipid values were similar for subjects with healthy periodontal status and those with gingivitis; however, subjects with healthy periodontal status had significantly lower TG values compared with subjects with $\mathrm{CP}(\mathrm{p}<0.01)$, and both subjects with healthy periodontal status and those with gingivitis had significantly higher HDL values compared with subjects with $\mathrm{CP}(\mathrm{p}<0.01)$. Similar to the normolipidemic groups, among the hyperlipidemic groups, serum lipid values were also similar for subjects with healthy periodontal status and those with gingivitis ( $p>0.05$ ); however, in contrast to the normolipidemic groups, HDL values for the

Table 1. Periodontal clinical measurements of sampling sites of the study groups.

\begin{tabular}{|c|c|c|c|c|c|c|c|}
\hline \multirow{2}{*}{ Clinical parameters } & $\mathrm{H}$ & G & $C P$ & $\mathrm{HH}$ & $H G$ & $\mathrm{HCP}$ & \multirow{2}{*}{$\mathrm{p}$-value } \\
\hline & $n=15$ & $n=15$ & $\mathrm{n}=15$ & $n=15$ & $n=15$ & $n=15$ & \\
\hline Age (years) & $38.30 \pm 4.84$ & $40.04 \pm 3.93$ & $42.17 \pm 3.1$ & $45.47 \pm 6.66$ & $41.0 \pm 5.91$ & $41.45 \pm 4.81$ & $0.205^{*}$ \\
\hline $\operatorname{Sex}(M / F)$ & $07 / 08$ & 07/08 & 09/06 & $07 / 08$ & 07/08 & 09/06 & $0.132^{\S}$ \\
\hline $\mathrm{Pl}$ & $0 \pm 0$ & $1.60 \pm 0.13$ & $2.10 \pm 0.18$ & $0 \pm 0$ & $1.75 \pm 0.60$ & $2.33 \pm 0.17$ & $0.001 *$ \\
\hline $\mathrm{GI}$ & $0 \pm 0$ & $1.23 \pm 0.11$ & $2.31 \pm 0.40$ & $0.23 \pm 0$ & $1.37 \pm 0.11$ & $2.01 \pm 0.53$ & $0.001^{*}$ \\
\hline $\mathrm{BOP}(\%)$ & $0 \pm 0$ & $71.00 \pm 1.78$ & $92.72 \pm 10.2$ & $0 \pm 0$ & $71.89 \pm 2.21$ & $93.85 \pm 1.92$ & $0.001 *$ \\
\hline PPD (mm) & $1.29 \pm 0.23$ & $1.91 \pm 0.09$ & $5.30 \pm 0.55$ & $1.39 \pm 0.06$ & $2.47 \pm 1.75$ & $5.64 \pm 0.30$ & $0.001 *$ \\
\hline $\mathrm{CAL}(\mathrm{mm})$ & $1.29 \pm 0.28$ & $1.91 \pm 0.09$ & $7.41 \pm 0.88$ & $1.39 \pm 0.06$ & $2.47 \pm 1.75$ & $8.82 \pm 0.68$ & $0.001 *$ \\
\hline
\end{tabular}

*Welch ANOVA test; §chi-square test; Values given as mean \pm standard error of mean, except sex. 
hyperlipidemic groups did not vary according to the periodontal status, but TG, TC, and LDL values were significantly higher for patients with hyperlipidemia with CP compared with those with gingivitis as well as those with healthy periodontal status $(\mathrm{p}<0.05)$.

For patients with hyperlipidemia and for normolipidemic subjects, GCF PC and MDA levels varied according to periodontal health status, with the highest levels in the groups with $\mathrm{CP}$ and the lowest levels in the groups with healthy periodontal status $[\mathrm{CP}>\mathrm{G}>\mathrm{H}(\mathrm{p}<0.01)$ and $\mathrm{HCP}>\mathrm{HG}>\mathrm{HH}(\mathrm{p}<0.01)]$. Conversely, the groups with $\mathrm{CP}$ had the lowest GCF TAOC levels, and those with healthy periodontal status had the highest $\mathrm{CP}$ levels $[\mathrm{CP}<\mathrm{G}<\mathrm{H}(\mathrm{p}<0.01)$ and $\mathrm{HCP}<\mathrm{HG}<\mathrm{HH}(\mathrm{p}<0.01)]$. Moreover, $\mathrm{PC}$ and MDA levels were significantly higher and TAOC levels were significantly lower among subjects with hyperlipidemia with CP compared with normolipidemic subjects with $\mathrm{CP}(\mathrm{p}<01)$ (Table 3).
Among normolipidemic subjects, GCF PC and MDA levels showed strong positive correlations with all clinical periodontal measurements and a moderate negative correlation with serum HDL levels; GCF TAOC levels also showed a strong negative correlation with all clinical periodontal measurements but a weak positive correlation with serum HDL levels among normolipidemic subjects (Table 4). Among patients with hyperlipidemia, GCF PC and MDA levels showed strong positive correlations with all clinical periodontal measurements; moderate positive correlations with serum TG, TC, and LDL levels; and moderate negative correlations with serum HDL levels. In contrast, GCF TAOC levels showed strong negative correlations with all clinical periodontal measurements; moderate negative correlations with serum TG, TC, and LDL levels; and weak positive correlation with serum HDL levels (Table 5).

Table 2. Serum lipid levels of subjects and GCF MDA, PC, and TAOC levels as total amount of sampling sites in the study groups.

\begin{tabular}{lcccccc}
\hline & \multicolumn{7}{c}{ Groups } \\
\cline { 2 - 7 } Biochemical parameters & $H$ & $G$ & CP & $H H$ & HG & HCP \\
\cline { 2 - 7 } & $n=15$ & $n=15$ & $n=15$ & $n=15$ & $n=15$ & $n=15$ \\
\hline Serum TG $(\mathrm{mg} / \mathrm{dL})$ & $71.8 \pm 7.09$ & $83.46 \pm 7.12$ & $109.33 \pm 8.24$ & $175.46 \pm 4.11$ & $175.80 \pm 2.37$ & $210.66 \pm 10.63$ \\
Serum TC $(\mathrm{mg} / \mathrm{dL})$ & $162.34 \pm 5.21$ & $147.62 \pm 3.68$ & $164.94 \pm 3.03$ & $252.38 \pm 4.28$ & $259.38 \pm 3.42$ & $279.19 \pm 4.36$ \\
Serum HDL $(\mathrm{mg} / \mathrm{dL})$ & $57.50 \pm 3.18$ & $56.30 \pm 3.38$ & $45.21 \pm 1.73$ & $50.25 \pm 1.67$ & $49.42 \pm 2.57$ & $44.14 \pm 2.01$ \\
Serum LDL $(\mathrm{mg} / \mathrm{dL})$ & $90.47 \pm 4.96$ & $91.31 \pm 3.72$ & $97.86 \pm 2.52$ & $167.04 \pm 3.78$ & $174.80 \pm 2.86$ & $192.91 \pm 3.78$ \\
GCF MDA $(\mu \mathrm{M})$ & $144.09 \pm 4.15$ & $298.52 \pm 18.90$ & $802.09 \pm 88.17$ & $139.50 \pm 3.40$ & $292.98 \pm 4.03$ & $899.73 \pm 16.58$ \\
GCF PC $(\mathrm{pM})$ & $0.05 \pm 0.002$ & $0.31 \pm 0.004$ & $1.91 \pm 0.081$ & $0.07 \pm 0.003$ & $0.41 \pm 0.019$ & $2.89 \pm 0.104$ \\
GCF TAOc $(\mu \mathrm{M})$ & $92.21 \pm 1.19$ & $78.32 \pm 0.84$ & $69.70 \pm 3.37$ & $90.32 \pm 0.74$ & $70.58 \pm 3.70$ & $54.12 \pm 1.06$ \\
\hline
\end{tabular}

Values given as mean \pm standard error of mean.

Table 3. Comparisons of blood serum and GCF biomarkers between the study groups ( $p$-value).

\begin{tabular}{lccccccc}
\hline Comparisons & $\begin{array}{c}\text { Serum TG } \\
(\mathrm{mg} / \mathrm{dL})\end{array}$ & $\begin{array}{c}\text { Serum TC } \\
(\mathrm{mg} / \mathrm{dL})\end{array}$ & $\begin{array}{c}\text { Serum HDL } \\
(\mathrm{mg} / \mathrm{dL})\end{array}$ & $\begin{array}{c}\text { Serum LDL } \\
(\mathrm{mg} / \mathrm{dL})\end{array}$ & $\begin{array}{c}\text { GCF MDA } \\
(\mu \mathrm{M})\end{array}$ & $\begin{array}{c}\text { GCF PC } \\
(\mathrm{pM})\end{array}$ & $\begin{array}{c}\text { GCF TAOc } \\
(\mu \mathrm{M})\end{array}$ \\
\hline $\mathrm{H}-\mathrm{G}$ & $p>0.05$ & $p>0.05$ & $p>0.05$ & $p>0.05$ & $0.001^{*}$ & $0.001^{*}$ & $0.001^{*}$ \\
H-CP & $0.002^{*}$ & $p>0.05$ & $0.001^{*}$ & $p>0.05$ & $0.001^{*}$ & $0.001^{*}$ & $0.001^{*}$ \\
G-CP & $p>0.05$ & $p>0.05$ & $0.002^{*}$ & $p>0.05$ & $0.001^{*}$ & $0.001^{*}$ & $0.001^{*}$ \\
HH-HG & $p>0.05$ & $p>0.05$ & $p>0.05$ & $p>0.05$ & $0.001^{*}$ & $0.001^{*}$ & $0.001^{*}$ \\
HH-HCP & $0.010^{*}$ & $0.000^{*}$ & $p>0.05$ & $0.000^{*}$ & $0.001^{*}$ & $0.001^{*}$ & $0.001^{*}$ \\
HG-HCP & $0.010^{*}$ & $0.016^{*}$ & $p>0.05$ & $0.016^{*}$ & $0.001^{*}$ & $0.001^{*}$ & $0.001^{*}$ \\
H-HH & $0.000^{*}$ & $0.000^{*}$ & $0.000^{*}$ & $0.000^{*}$ & $p>0.05$ & $p>0.05$ & $p>0.05$ \\
G-HG & $0.000^{*}$ & $0.000^{*}$ & $0.000^{*}$ & $0.000^{*}$ & $p>0.05$ & $p>0.05$ & $p>0.05$ \\
CP-HCP & $0.000^{*}$ & $0.000^{*}$ & $0.000^{*}$ & $0.000^{*}$ & $0.001^{*}$ & $0.005^{*}$ & $0.001^{*}$ \\
\hline
\end{tabular}

*: Welch ANOVA test $(p<0.05)$, post-hoc Tamhane's T2 test 
Table 4. Correlations between periodontal clinical measurements and biochemical parameters in normolipidemic subjects.

\begin{tabular}{|c|c|c|c|c|c|c|c|c|c|}
\hline \multirow{4}{*}{ Variable } & \multicolumn{9}{|c|}{ Normolıpıdemıc subjects ( $n=45$ ) } \\
\hline & \multirow{3}{*}{$\mathrm{PI}$} & \multirow{3}{*}{$\mathrm{Gl}$} & \multirow{3}{*}{$\mathrm{BOP} \%$} & \multirow{3}{*}{$\mathrm{PPD}(\mathrm{mm})$} & \multicolumn{2}{|l|}{$r$ values } & \multirow{3}{*}{$\begin{array}{c}\text { Serum TC } \\
(\mathrm{mg} / \mathrm{dL})\end{array}$} & \multirow{3}{*}{$\begin{array}{c}\text { Serum HDL } \\
\text { (mg/dL) }\end{array}$} & \multirow{3}{*}{$\begin{array}{c}\text { Serum LDL } \\
(\mathrm{mg} / \mathrm{dL})\end{array}$} \\
\hline & & & & & & Serum TG & & & \\
\hline & & & & & $\mathrm{CAL}(\mathrm{mm})$ & $(\mathrm{mg} / \mathrm{dL})$ & & & \\
\hline $\begin{array}{l}\text { GCF MDA } \\
(\mu \mathrm{M})\end{array}$ & $0.713^{*}$ & $0.704^{*}$ & $0.660^{*}$ & $0.858^{*}$ & $0.868^{*}$ & $0.433^{*}$ & NS & $-0.464^{*}$ & NS \\
\hline $\begin{array}{l}\text { GCF PC } \\
(\mathrm{pM})\end{array}$ & $0.571^{*}$ & $0.566^{*}$ & $0.505^{*}$ & $0.770^{*}$ & $0.842^{*}$ & $0.456^{*}$ & NS & $-0.465^{*}$ & NS \\
\hline $\begin{array}{l}\text { GCF TAOC } \\
(\mu \mathrm{M})\end{array}$ & $-0.713^{*}$ & $-0.740^{*}$ & $-0.770^{*}$ & $-0.640^{*}$ & $-0.693^{*}$ & NS & NS & $0.393^{* *}$ & NS \\
\hline
\end{tabular}

*Pearson's correlation test, significant at the 0.01 level; **Pearson's correlation test, significant at the 0.05 level; NS: not significant.

Table 5. Correlations between periodontal clinical measurements and biochemical parameters in subjects with hyperlipidemia.

\begin{tabular}{|c|c|c|c|c|c|c|c|c|c|}
\hline \multirow{4}{*}{ Variable } & \multicolumn{9}{|c|}{ SUBJECTS WITH HYPERLIPIDEMIA $(\mathrm{n}=45)$} \\
\hline & \multirow{3}{*}{$\mathrm{Pl}$} & & & & r values & & & & \\
\hline & & \multirow{2}{*}{$\mathrm{Gl}$} & $\mathrm{BOP}$ & \multirow{2}{*}{ PPD (mm) } & \multirow{2}{*}{ CAL (mm) } & \multirow{2}{*}{$\begin{array}{c}\text { Serum TG } \\
(\mathrm{mg} / \mathrm{dL})\end{array}$} & \multirow{2}{*}{$\begin{array}{c}\text { Serum TC } \\
(\mathrm{mg} / \mathrm{dL})\end{array}$} & \multirow{2}{*}{$\begin{array}{c}\text { Serum HDL } \\
\text { (mg/dL) }\end{array}$} & \multirow{2}{*}{$\begin{array}{c}\text { Serum LDL } \\
(\mathrm{mg} / \mathrm{dL})\end{array}$} \\
\hline & & & $\%$ & & & & & & \\
\hline $\begin{array}{l}\text { GCF MDA } \\
(\mu \mathrm{M})\end{array}$ & $0.724^{*}$ & $0.746^{*}$ & $0.738^{*}$ & $0.976^{*}$ & $0.979^{*}$ & $0.591^{*}$ & $0.558^{*}$ & $-0.323^{* *}$ & $0.625^{*}$ \\
\hline $\begin{array}{l}\text { GCF PC } \\
(\mathrm{pM})\end{array}$ & $0.685^{*}$ & $0.762^{*}$ & $0.773^{*}$ & $0.834^{*}$ & $0.975^{*}$ & $0.643^{*}$ & $0.567^{*}$ & $-0.372^{* *}$ & $0.594^{*}$ \\
\hline $\begin{array}{l}\text { GCF TAOC } \\
(\mu \mathrm{M})\end{array}$ & $-0.825^{*}$ & $-0.817^{*}$ & $-0.849^{*}$ & $-0.836^{*}$ & $-0.891^{*}$ & $-0.476^{*}$ & $0.575^{*}$ & $0.261^{* *}$ & $-0.623^{*}$ \\
\hline
\end{tabular}

*Pearson's correlation test, significant at the 0.01 level; ${ }^{* *}$ Pearson's correlation test, significant at the 0.05 level; NS: not significant.

\section{Discussion}

This study evaluated GCF PC, MDA, and TAOC levels relating to periodontal pathology and hyperlipidemia. Several previous studies have investigated the association between periodontal disease and serum lipids, but systemically healthy subjects with periodontitis have been determined mostly in those researches. ${ }^{15,25,26}$ Studies examining the periodontal status of subjects with hyperlipidemia, although limited, have all reported an association between periodontal status and serum lipids in the hyperlipidemic population. ${ }^{11,27,28,29}$ However, this study is the first known published study that examined the relationship between periodontal disease and hyperlipidemia using changes in GCF oxidative status, which reflects local effects of hyperlipidemia in periodontal tissue rather than in the blood serum.

In this study, paired comparisons between hyperlipidemic and normolipidemic groups with similar periodontal status showed that clinical parameters were not significantly affected by serum lipid levels, although PPD and CAL measurements were slightly higher among subjects with hyperlipidemia than with normolipidemic subjects with similar periodontal status. These findings contradict those of previous studies reporting an association between hyperlipidemia and periodontal clinical status and concluding that hyperlipidemia is responsible for increases in PPD, CAL, BOP and other periodontal measurements. ${ }^{11,27,28}$ The differences in findings between our study and those of previous studies may be related to differences in the study design. Our study examined groups of subjects with gingivitis in addition to subjects with periodontitis and subjects with healthy periodontal status; however, distinct gingivitis-periodontitis and periodontally healthy groups were not included in these previous studies, except in the study by Fentoğlu et al..$^{29}$ In that study, although not matching our group designs exactly, the investigators grouped participants according to the periodontal status (gingivitis, periodontitis, and periodontally healthy) as well as by hyperlipidemia treatment (dietary vs drug treatment), and no apparent 
effect of serum lipid levels on clinical periodontal measurements was found, which is in line with the findings of our study. In general, given the differences in the participant-selection criteria and constitution of study groups among studies, drawing any meaningful comparisons between findings is difficult as well as inappropriate. However, regarding the similarities in clinical measurements of patients with hyperlipidemia and normolipidemic subjects found in our study, it is possible that subjects with hyperlipidemia who participated in the study had not been in a hyperlipidemic state long enough for their condition to have created an inflammatory burden severe enough to be reflected in changes in clinical parameters. ${ }^{30}$

Although our study found similarities in clinical periodontal parameters for patients with hyperlipidemia and normolipidemic subjects, serum TG, LDL, and TC levels in both hyperlipidemic and normolipidemic groups were higher for subjects with $\mathrm{CP}$ compared with subjects with both gingivitis and periodontally healthy subjects. Serum HDL levels were also lower; however, for subjects with CP compared with subjects with both gingivitis and periodontally healthy subjects, the differences were only significant for normolipidemic subjects. Our findings for serum TG, LDL, and TC levels are comparable with those of Penumarthy et al., ${ }^{31}$ who reported significantly higher serum TG, TC, and LDL levels and significantly lower HDL levels among systemically healthy subjects with periodontitis compared with subjects with gingivitis and healthy periodontal status. Given that chronic local and acute systemic infections have been shown to alter lipid metabolism, manifesting primarily in lipid peroxidation and elevated TG, LDL, and free fatty acid levels, ${ }^{32}$ it is not surprising that increases in serum LDL, TGL, and TC levels have been observed with periodontal disease, which is considered to be a "low-grade subclinical systemic inflammation." Unlike other lipid subfractions, HDL is an anti-inflammatory whose catabolism is heightened by infection. ${ }^{30}$ Our findings for HDL levels are in line with those of Wakai et al. ${ }^{33}$ who found decreases in serum HDL levels to be associated with increases in Community Periodontal Index of Treatment Needs scores, and Fentoğlu et al., ${ }^{28}$ who found decreases in HDL levels to be associated with increases in attachment loss.
In our study, GCF PC and MDA levels were significantly higher and GCF TAOC levels were significantly lower in both the hyperlipidemic and normolipidemic CP groups compared with the gingivitis and periodontally healthy groups, whereas paired comparisons between normolipidemic subjects and patients with hyperlipidemia of similar periodontal status showed that these OS markers indicated significant differences only in the periodontitis groups. These results are in accordance with those of several studies reporting that oxidative injury and stress associated with inflammatory response and periodontal deterioration lead to increases in GCF and salivary lipid peroxidation and PC and MDA levels as well as decreases in TAOC levels. ${ }^{2,3,434,35}$. To the best of our knowledge, our study is the first to evaluate GCF oxidative status in patients with hyperlipidemia with varying degrees of periodontal pathology. In what appears to be the only previous clinical study to examine oxidative changes in patients with hyperlipidemia in relation to periodontal status, Fentoğlu at al. ${ }^{11}$ evaluated serum MDA and 8-OHdG levels and their correlations with lipid profiles. Based on their findings, the investigators suggested a significant relationship between periodontal destruction and abnormal serum lipid levels.

In addition to the significant changes in oxidative status seen in the our study relating to periodontal disease, especially among subjects with hyperlipidemia, positive correlations were found between GCF PC and MDA levels and clinical parameters (i.e., PPD, $\mathrm{CAL}$, and BOP measurements) as well as between serum lipid subfractions and clinical parameters, whereas negative correlations were found between GCF TAOC levels and clinical parameters. Previous studies that examined clinical measurements without investigating GCF biological markers reported similar associations between serum TC and LDL levels and PPD measurements, ${ }^{15,16}$ serum TC and LDL levels and CAL measurements, ${ }^{27}$ and serum HDL levels and clinical periodontal measurements. ${ }^{28,29,31}$ The authors claimed these correlations to be a proof of the relationship between abnormal lipid subfraction levels and ongoing processes of periodontal destruction. Furthermore, the changes seen in OS markers were presented as a sign of alterations in tissue response occurring in connection with a hyperlipidemic state. Hyperlipidemia 
has been suggested to cause hyperactivity of white blood cells. ${ }^{7}$ Given that neutrophil respiratory bursts have been shown to increase in patients with hyperlipidemia ${ }^{7,11,25}$ and that polymorphonuclear priming and/or hyperfunction have been reported to lead to heightened proinflammatory activity, including increases in OS, hyperlipidemia may be associated with progressive periodontal disease. ${ }^{36,37}$ In addition to their connection with neutrophil hyper-reactivity, serum lipid levels may play an extremely important role in the pathogenesis of inflammatory diseases such as periodontal disease through the cellular signalization activity of phospholipids contained in cell membranes. By interfering directly with membrane-bound receptors and altering gene expression, serum lipids play a role in tissue response, which when compromised, may predispose a patient to periodontal disease or exaggerated periodontal destruction. ${ }^{38,39}$ This study's finding of higher OS markers and lower TAOC levels in patients with hyperlipidemia with periodontitis compared with patients with normolipidemia with periodontitis may be an indication of alterations in tissue response caused by lipid mediators at this later stage of periodontal destruction.

Although there appears to be a relationship between periodontitis and hyperlipidemia, it is unclear if periodontal pathology affects lipid metabolism or if conditions associated with hyperlipidemia have a detrimental effect on periodontal tissue..$^{25,38,39,40}$ Our study found that patients with hyperlipidemia with periodontitis had higher GCF PC and MDA levels and lower GCF TAOC levels compared with systemically healthy subjects with periodontitis. Moreover, serum lipid levels varied according to periodontal status, but the difference was more pronounced among patients with hyperlipidemia than with normolipidemic subjects. The higher OS markers in the GCF of patients with hyperlipidemia compared with normolipidimic subjects, regardless of periodontal health status, correlated with higher serum lipid levels. It has been claimed that the changes in lipid metabolism affect the host susceptibility via OS-related periodontal destruction. ${ }^{25,38,39}$ In conclusion, increased OS and decreased TAOC level in the GCF of patients with hyperlipidemia and periodontal disease combination may be the possible cause of the alteration of host susceptibility to periodontal inflammation. Moreover, the bidirectional relationship between local periodontal and systemic factors should be taken into consideration in the treatment of patients with periodontal disease.

\section{Ethical approval}

All procedures performed in this study involving human participants were in accordance with the ethical standards of the Ondokuz Mayis University research committee and with the 1964 Helsinki Declaration and its later amendments or comparable ethical standards. In addition, the research protocol was registered at ClinicalTrials.gov (Registration identification: NCT02808130).

\section{References}

\footnotetext{
1. Bullon P, Newman HN, Battino M. Obesity, diabetes mellitus, atherosclerosis and chronic periodontitis: a shared pathology via oxidative stress and mitochondrial dysfunction? Periodontol 2000. 2014;64(1):139-53. https://doi.org/10.1111/j.1600-0757.2012.00455.x

2. Baltacioğlu E, Akalin FA, Alver A, Değer O, Karabulut $E$. Protein carbonyl levels in serum and gingival crevicular fluid in patients with chronic periodontitis. Arch Oral Biol. 2008;53(8):716-22. https://doi.org/10.1016/i.archoralbio.2008.02.002

3. Baltacıoğlu E, Kehribar MA, Yuva P, Alver A, Atagün OS, Karabulut $E$ et al. Total oxidant status and bone resorption biomarkers in serum and gingival crevicular fluid of patients
}

\footnotetext{
with periodontitis. J Periodontol. 2014;85(2):317-26. https://doi.org/10.1902/jop.2013.130012

4. Baltacıoğlu E, Yuva P, Aydın G, Alver A, Kahraman C, Karabulut $E$ et al. Lipid peroxidation levels and total oxidant/antioxidant status in serum and saliva from patients with chronic and aggressive periodontitis. Oxidative stress index: a new biomarker for periodontal disease? J Periodontol. 2014;85(10):1432-41. https://doi.org/10.1902/jop.2014.130654

5. Torumtay G, Kırzıoğlu FY, Öztürk Tonguç M, Kale B, Calapoğlu M, Orhan H. Effects of periodontal treatment on inflammation and oxidative stress markers in patients with metabolic syndrome. J Periodontal Res. 2016;51(4):489-98. https://doi.org/10.1111/ire.12328
} 
6. Korhonen S, Saxlin T, Suominen L, Jula A, Knuuttila M, Ylöstalo P. Serum cholesterol ratios and periodontal infection: results of the Health 2000 Survey. J Clin Periodontol. 2011;38(9):787-94. https://doi.org/10.1111/j.1600-051X.2011.01758.x

7. Krause S, Brachmann P, Brandes C, Lösche W, Hoffmann T, Gängler P. Aggregation behaviour of blood granulocytes in patients with periodontal disease. Arch Oral Biol. 1990;35(1):757. https://doi.org/10.1016/0003-9969(90)90119-U

8. Le Lay S, Simard G, Martinez MC, Andriantsitohaina R. Oxidative stress and metabolic pathologies: from an adipocentric point of view. Oxid Med Cell Longev. 2014;2014:908539. https://doi.org/10.1155/2014/908539

9. Ekuni D, Tomofuji T, Tamaki N, Sanbe T, Azuma T, Yamanaka R et al. Mechanical stimulation of gingiva reduces plasma $8-\mathrm{OHdG}$ level in rat periodontitis. Arch Oral Biol. 2008;53(4):324-9. https://doi.org/10.1016/i.archoralbio.2007.10.005

10. Canakçi CF, Canakçi V, Tatar A, Eltas A, Sezer U, Ciçek Y et al. Increased salivary level of 8 -hydroxydeoxyguanosine is a marker of premature oxidative mitochondrial DNA damage in gingival tissue of patients with periodontitis. Arch Immunol Ther Exp (Warsz). 2009;57(3):205-11. https://doi.org/10.1007/s00005-009-0026-9

11. Fentoğlu Ö, Kırzıoğlu FY, Bulut MT, Kumbul Doğuç D, Kulaç $E$, Önder $C$ et al. Evaluation of lipid peroxidation and oxidative DNA damage in patients with periodontitis and hyperlipidemia. J Periodontol. 2015 May;86(5):682-8. https://doi.org/10.1902/jop.2015.140561

12. Chevion M, Berenshtein E, Stadtman ER. Human studies related to protein oxidation: protein carbonyl content as a marker of damage. Free Radic Res. 2000;33 Suppl:S99-108.

13. Del Rio D, Stewart AJ, Pellegrini N. A review of recent studies on malondialdehyde as toxic molecule and biological marker of oxidative stress. Nutr Metab Cardiovasc Dis. 2005;15(4):31628. https://doi.org/10.1016/i.numecd.2005.05.003

14. Erel O. A novel automated method to measure total antioxidant response against potent free radical reactions. Clin Biochem. 2004;37(2):112-9. https://doi.org/10.1016/i.clinbiochem.2003.10.014

15. Lösche W, Karapetow F, Pohl A, Pohl C, Kocher T. Plasma lipid and blood glucose levels in patients with destructive periodontal disease. J Clin Periodontol. 2000;27(8):537-41. https://doi.org/10.1034/j.1600-051x.2000.027008537.x

16. Katz J, Flugelman MY, Goldberg A, Heft M. Association between periodontal pockets and elevated cholesterol and low density lipoprotein cholesterol levels. J Periodontol. 2002;73(5):494-500. https://doi.org/10.1902/jop.2002.73.5.494

17. Lösche W, Marshal GJ, Apatzidou DA, Krause S, Kocher T, Kinane DF. Lipoprotein-associated phospholipase $A_{2}$ and plasma lipids in patients with destructive periodontal disease. J Clin Periodontol. 2005;32(6):640-4. https://doi.org/10.1111/j.1600-051X.2005.00725.x

18. Machado AC, Quirino MR, Nascimento LF. Relation between chronic periodontal disease and plasmatic levels of triglycerides, total cholesterol and fractions. Braz Oral Res. 2005;19(4):284-9. https://doi.org/10.1590/S1806-83242005000400009

19. Saxlin T, Suominen-Taipale L, Kattainen A, Marniemi J, Knuuttila M, Ylöstalo P. Association between serum lipid levels and periodontal infection. J Clin Periodontol. 2008;35(12):1040-7. https://doi.org/10.1111/j.1600-051X.2008.01331.x

20. Tomofuji T, Azuma T, Kusano H, et al . Oxidative damage of periodontal tissue in the rat periodontitis model: effects of a high-cholesterol diet. FEBS Lett. 2006;580(15):3601-3604. https://doi.org/10.1016/i.febslet.2006.05.041.

21. Silness J, Löe H. Periodontal disease in Pregnancy. II. Correlation between oral hygiene and periodontal condition. Acta Odontol Scand. 1964;22(1):121-35. https://doi.org/10.3109/00016356408993968

22. Löe H, Silness J. Periodontal disease in Pregnancy.l. Prevalance and severity. Acta Odontol Scand. 1963;21(6):533-51. https://doi.org/10.3109/00016356309011240

23. Grundy SM, Cleeman JI, Merz CN, Brewer HB Jr, Clark LT, Hunninghake DB et al. Implications of recent clinical trials for the National Cholesterol Education Program Adult Treatment Panel III. Guidelines. J Am Coll Cardiol. 2004;44(3):720-32. https://doi.org/10.1161/01.CIR.0000133317.49796.0E

24. Curtis MA, Griffiths GS, Price SJ, Coulthurst SK, Johnson NW. The total protein concentration of gingival crevicular fluid. Variation with sampling time and gingival inflammation. J Clin Periodontol. 1988;15(10):628-32. https://doi.org/10.1111/j.1600-051X.1988.tb02263.x

25. Cutler CW, Shinedling EA, Nunn M, Jotwani R, Kim BO, Nares $S$ et al. Association between periodontitis and hyperlipidemia: cause or effect? J Periodontol. 1999;70(12):142934. https://doi.org/10.1902/jop.1999.70.12.1429

26. Moeintaghavi A, Haerian-Ardakani A, Talebi-Ardakani M, Tabatabaie I. Hyperlipidemia in patients with periodontitis. J Contemp Dent Pract. 2005;6(3):78-85.

27. Awartani F, Atassi F. Evaluation of periodontal status in subjects with hyperlipidemia. J Contemp Dent Pract. 2010;11(2):33-40.

28. Fentoğlu O, Oz G, Taşdelen P, Uskun E, Aykaç Y, Bozkurt FY. Periodontal status in subjects with hyperlipidemia. J Periodontol. 2009;80(2):267-73. https://doi.org/10.1902/jop.2009.080104

29. Fentoğlu Ö, Köroğlu BK, Hiçyılmaz H, Sert T, Özdem $M$, Sütçü R et al. Pro-inflammatory cytokine levels in association between periodontal disease and hyperlipidaemia. J Clin Periodontol. 2011;38(1):8-16. https://doi.org/10.1111/j.1600-051X.2010.01644.x

30. O'Neill F, Riwanto M, Charakida M, Colin S, Manz J, McLoughlin E et al. Structural and functional changes in $\mathrm{HDL}$ with low grade and chronic inflammation. Int J Cardiol. 2015;188:111-6. https://doi.org/10.1016/i.ijcard.2015.03.058

31. Penumarthy S, Penmetsa GS, Mannem S. Assessment of serum levels of triglycerides, total cholesterol, high-density lipoprotein cholesterol, and low-density lipoprotein cholesterol in periodontitis patients. J Indian Soc Periodontol. 2013 Jan;17(1):30-5. https://doi.org/10.4103/0972-124X.107471 
32. Fentoglu O, Bozkurt FY. The bi-directional relationship between periodontal disease and hyperlipidemia.

Eur J Dent. 2008;2(2):142-6.

33. Wakai K, Kawamura T, Umemura O, Hara Y, Machida J, Anno T et al. Associations of medical status and physical fitness with periodontal disease. J Clin Periodontol.;26(10):664-72. https://doi.org/10.1034/i.1600-051X.1999.261006.x

34. Akalin FA, Baltacioğlu E, Alver A, Karabulut E. Lipid peroxidation levels and total oxidant status in serum, saliva and gingival crevicular fluid in patients with chronic periodontitis. J Clin Periodontol. 2007;34(7):558-65. https://doi.org/10.1111/j.1600-051X.2007.01091.x

35. Wei D, Zhang XL, Wang YZ, Yang CX, Chen G. Lipid peroxidation levels, total oxidant status and superoxide dismutase in serum, saliva and gingival crevicular fluid in chronic periodontitis patients before and after periodontal therapy. Aust Dent J. 2010;55(1):708. https://doi.org/10.1111/j.1834-7819.2009.01123.x

36. Kantarci A, Oyaizu K, Van Dyke TE. Neutrophil-mediated tissue injury in periodontal disease pathogenesis: findings from localized aggressive periodontitis. J Periodontol. 2003;74(1):66-75. https://doi.org/10.1902/jop.2003.74.1.66

37. Nussbaum G, Shapira L. How has neutrophil research improved our understanding of periodontal pathogenesis? J Clin Periodontol. 2011;38 Suppl 11:49-59. https://doi.org/10.1111/j.1600-051X.2010.01678.x

38. Chen S, Lin G, You X, Lei L, Li Y, Lin M et al. Hyperlipidemia causes changes in inflammatory responses to periodontal pathogen challenge: implications in acute and chronic infections. Arch Oral Biol. 2014;59(10):1075-84. https://doi.org/10.1016/i.archoralbio.2014.06.004

39. Lei L, Li H, Yan F, Xiao Y. Hyperlipidemia impaired innate immune response to periodontal pathogen porphyromonas gingivalis in apolipoprotein E knockout mice. PLoS One. 2013;8(8):e71849.

40. Jaramillo A, Lafaurie GI, Millán LV, Martin Ardila C, Duque A, Novoa $C$ et al. Association between periodontal disease and plasma levels of cholesterol and triglycerides. Colomb Med (Cali). 2013;44(2):80-6. 